\title{
Bariatric surgery: the challenges with candidate selection, individualizing treatment and clinical outcomes
}

\author{
KJ Neff ${ }^{1}$, T Olbers $^{2,3}$ and CW le Roux ${ }^{1,3^{*}}$
}

\begin{abstract}
Obesity is recognized as a global health crisis. Bariatric surgery offers a treatment that can reduce weight, induce remission of obesity-related diseases, and improve the quality of life. In this article, we outline the different options in bariatric surgery and summarize the recommendations for selecting and assessing potential candidates before proceeding to surgery. We present current data on post-surgical outcomes and evaluate the psychosocial and economic effects of bariatric surgery. Finally, we evaluate the complication rates and present recommendations for post-operative care.

Keywords: Bariatric surgery, obesity, pre-operative assessment, postoperative outcomes.
\end{abstract}

\section{Background}

The rates of obesity are increasing with at least 300 million people worldwide now classified as obese [1]. Obesity is associated with reduced life expectancy, increased morbidity and mortality, and greater healthcare costs $[2,3]$. Bariatric surgery is more effective than non-surgical treatments of obesity with a reduction in overall mortality of $30 \%$ demonstrated in surgical recipients [4-7]. Greater reductions are seen in cancer and diabetes mortality $[6,7]$.

Recommendations for referring candidates for bariatric surgery are available but they seldom give guidance to help a specific patient. We will examine the evidence for the magnitude and duration of the positive effects and negative side effects of bariatric surgery. Finally, we will offer a synopsis of the data on post-operative

\footnotetext{
* Correspondence: c.leroux@imperial.ac.uk

${ }^{1}$ Experimental Pathology, UCD Conway Institute, School of Medicine and

Medical Sciences, University College Dublin, Belfield, Dublin 4, Dublin, Ireland Full list of author information is available at the end of the article
}

outcomes, and on what to expect in the months and years following surgery.

\section{Review}

Individualizing treatment

Available options in bariatric surgery

Several bariatric procedures are available. The most commonly performed procedures are Roux-en-Y gastric bypass (RYGB), adjustable gastric banding (AGB), and sleeve gastrectomy (SG) [8]. Biliopancreatic diversion, with or without duodenal switch (BPD and BPD-DS), is less commonly performed but is often considered in extremely obese individuals [9]. All procedures can be performed laparoscopically with a lower rate of complications such as wound infection and incisional hernias [10].

In RYGB, the stomach is divided into an upper gastric pouch, which is 15 to $30 \mathrm{~mL}$ in volume and a lower gastric remnant. The gastric pouch is anastomosed to the jejunum after it has been divided some 30 to $75 \mathrm{~cm}$ distal to the ligament of Treitz; this distal part is brought up as a 'Roux-limb'. The excluded biliary limb, including the gastric remnant, is connected to the bowel some 75 to 150 $\mathrm{cm}$ distal to the gastrojejunostomy (see Figure 1).

In AGB, a band with an inner inflatable silastic balloon is placed around the proximal stomach just below the gastroesophageal junction. The band can be tightened through a subcutaneous access port by the injection or withdrawal of a saline solution [11] (see Figure 2).

In SG, the stomach is transected vertically over a 34 or $36 \mathrm{~F}$ bougie creating a gastric tube and leaving a pouch of 100 to $200 \mathrm{~mL}$ (see Figure 3). Although many regard SG as a restrictive procedure, it is increasingly recognized as a metabolic procedure [12].

BPD involves a partial gastrectomy that results in a 400 $\mathrm{mL}$ gastric pouch [13]. The small bowel is divided $250 \mathrm{~cm}$ proximal to the ileocecal valve, and the alimentary limb is connected to the gastric pouch to create a Roux-en-Y
C Biomed Central 


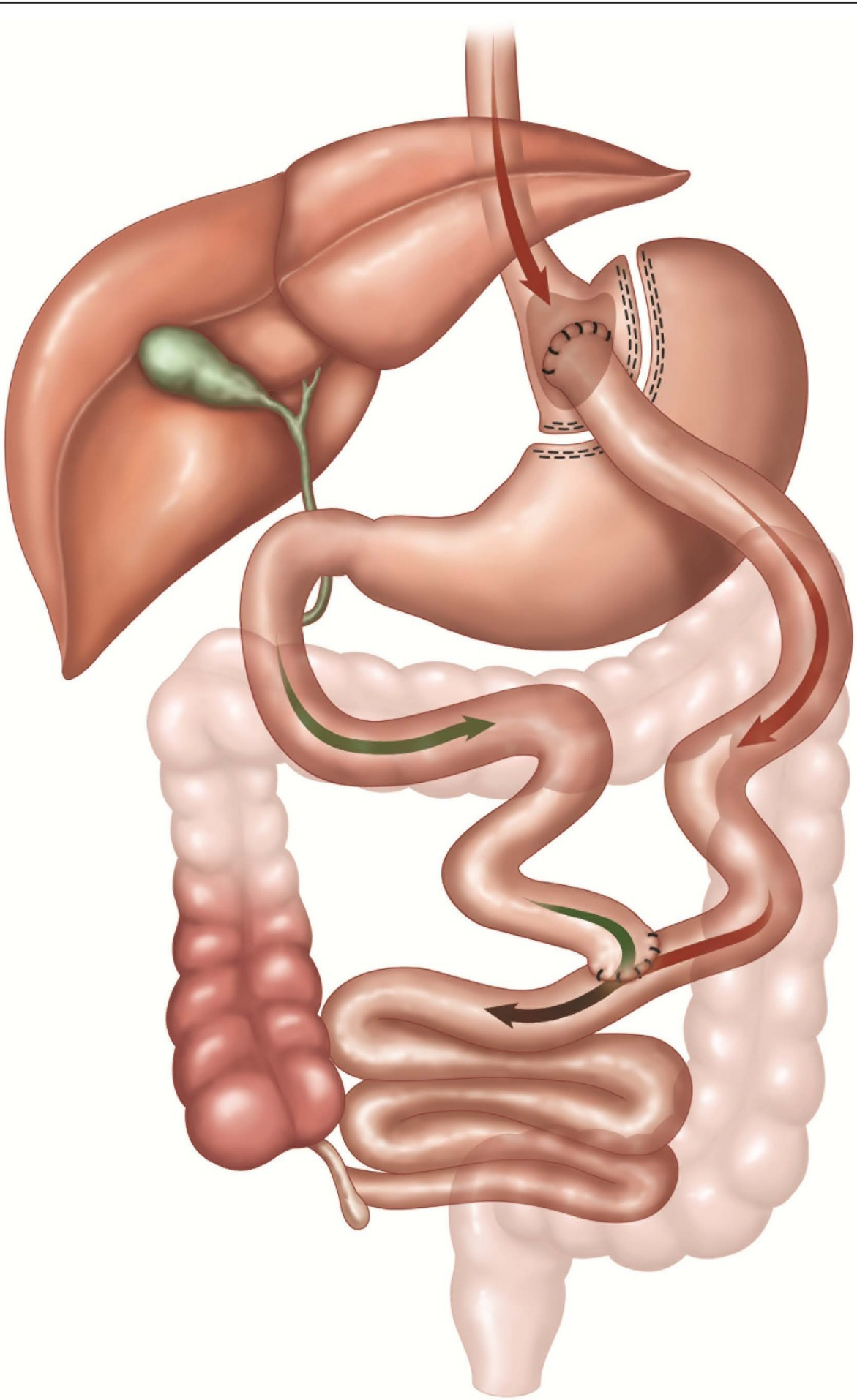

Figure 1 RYGB: Roux-en-Y gastric bypass. An upper gastric pouch, of 15 to $30 \mathrm{~mL}$ in volume, and a lower gastric remnant is formed from the stomach. The jejunum is divided some 30 to $75 \mathrm{~cm}$ distal to the ligament of Treitz, and anastomosed to the gastric pouch. The distal jejunum is brought up as a 'Roux-limb'. The excluded biliary limb, including the gastric remnant, is anastomosed to the bowel some 75 to $150 \mathrm{~cm}$ distal to the gastrojejunostomy. The included figures are the property of Johnson and Johnson and Ethicon Endo-Surgery (Europe). They are reproduced here with their kind permission. 


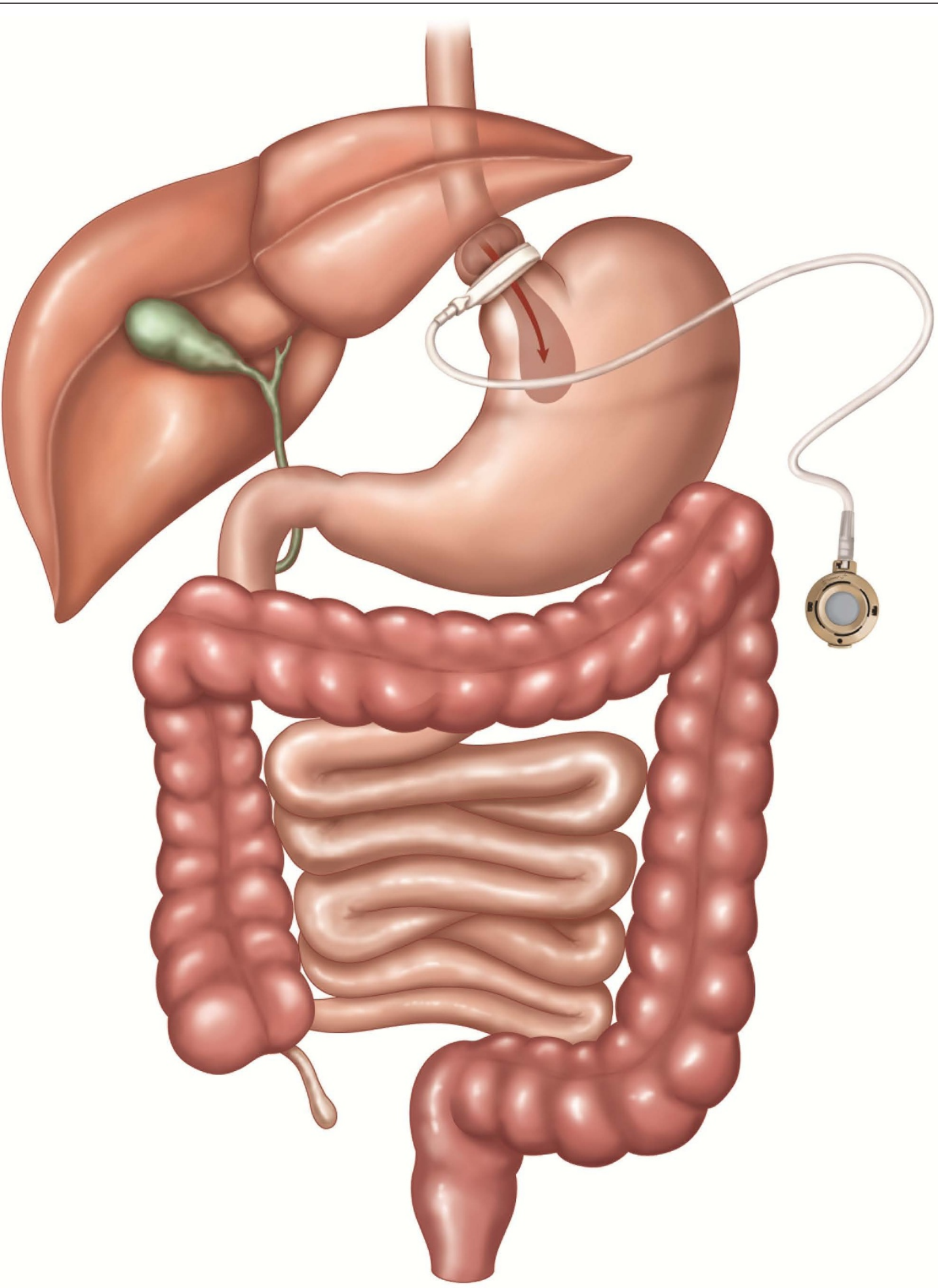

Figure 2 AGB: Adjustable gastric band. A band with an inner inflatable silastic balloon is placed around the proximal stomach just below the gastroesophageal junction. The band is adjusted through a subcutaneous access port by the injection or withdrawal of solution. The included figures are the property of Johnson and Johnson and Ethicon Endo-Surgery (Europe). They are reproduced here with their kind permission. 


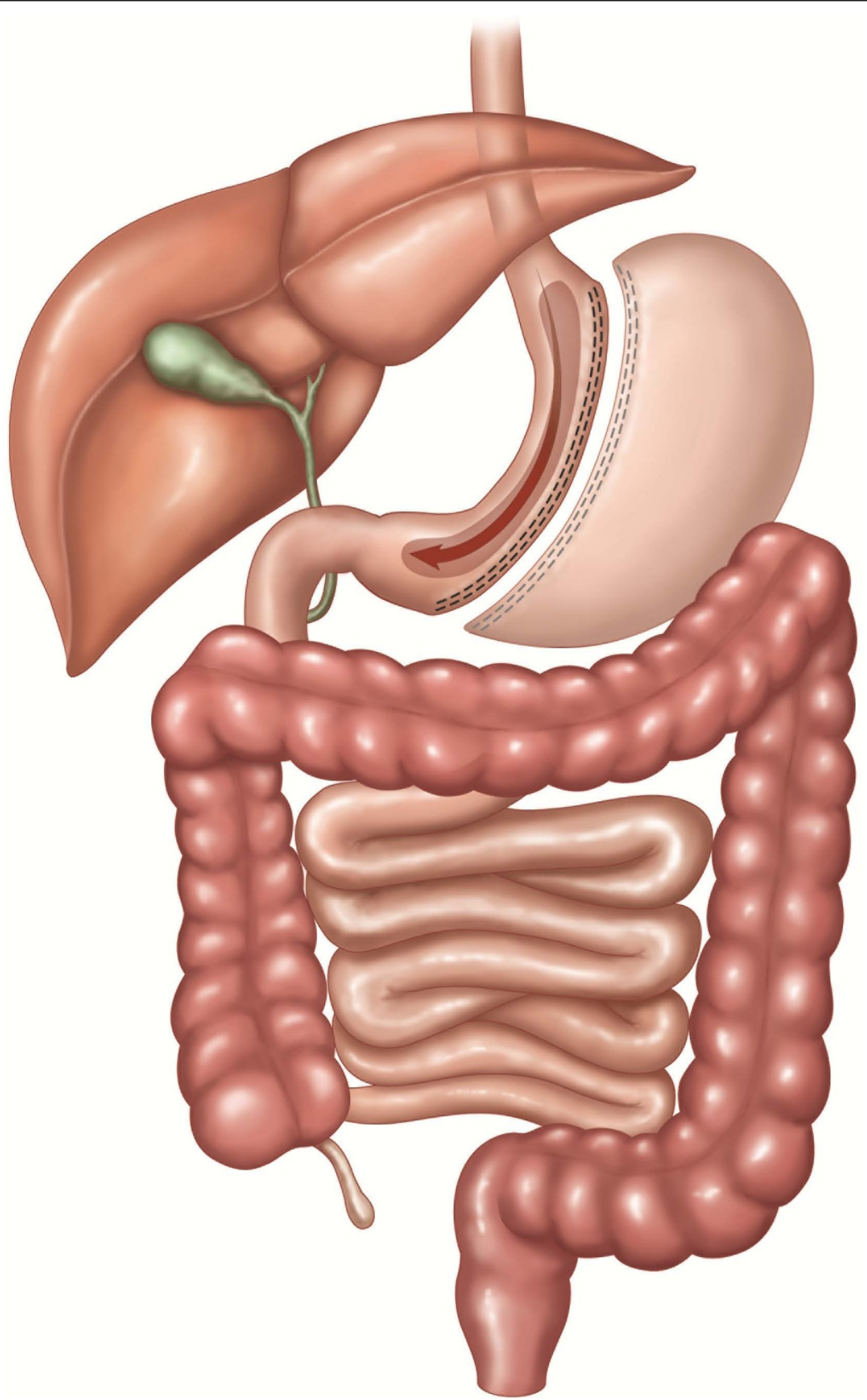

Figure 3 SG: Sleeve gastrectomy. The stomach is transected vertically creating a gastric tube and leaving a pouch of 100 to $200 \mathrm{~mL}$. The included figures are the property of Johnson and Johnson and Ethicon Endo-Surgery (Europe). They are reproduced here with their kind permission. 
gastroenterostomy. An anastomosis is performed between the excluded biliopancreatic limb and the alimentary limb $50 \mathrm{~cm}$ proximal to the ileocecal valve (see Figure 4). In BPD-DS, a vertical SG is constructed and the division of the duodenum is performed immediately beyond the pylorus. The alimentary limb is connected to the duodenum, whereas the iliopancreatic limb is anastomosed to the ileum $75 \mathrm{~cm}$ proximal to the ileocecal valve [14].

Endoscopically placed synthetic duodenojejunal bypass liners such as the EndoBarrier ${ }^{\circledR}$ have been recently developed and are associated with a mean weight loss of $10 \%$ to $20 \%[15,16]$. These devices establish duodenal exclusion and result in greater weight loss than diet and exercise alone up to 12 weeks post-insertion [17]. They may also improve glycemic control in those with type 2 diabetes mellitus (T2DM) [18].

However, long-term data remain to be reported and the device is often poorly tolerated [18]. Complications include sleeve migration and obstruction, which can occur with a frequency of $15 \%$ to $20 \%[15,16,18]$. It can also be difficult to insert the device with placement failure in up to $13 \%$ [18]. While the concept of endoscopic techniques such as Endobarrier ${ }^{\circledR}$ remains attractive, the permanence of the weight loss and the clinical role of the device itself remain to be determined.

Other techniques for the treatment of obesity include the intra-gastric balloon, which can be effective for short-term weight loss [16]. However, these newer techniques remain in the experimental realm and data on long-term clinical efficacy are not available. The EndoBarrier $^{\circledR}$ may not be any better or worse than gastric balloons or very low calorie diets at reducing operative risk in patients with extreme obesity. The device may be developed for use in those with diabetes and obesity who decline laparoscopic bariatric surgery. If other nonsurgical treatments such as exogenous satiety gut hormones, or weight loss maintenance diets, can show that the weight loss after removal of the EndoBarrier ${ }^{\mathbb{R}}$ can be maintained, then a comparison with established bariatric procedures may be feasible.

\section{Candidate selection and pre-operative assessment}

Patient selection criteria for bariatric surgery include body mass index (BMI), the presence of co-morbidities and a history of prior weight loss attempts. National Institute of Clinical Excellence (NICE) and National Institutes of Health (NIH) guidelines state that bariatric surgery should be offered to patients with a BMI of 35 to $40 \mathrm{~kg} / \mathrm{m}^{2}$ who have obesity related conditions such as diabetes mellitus or obstructive sleep apnea, or in those with a BMI of $40 \mathrm{~kg} / \mathrm{m}^{2}$ or greater regardless of weight related co-morbidities $[19,20]$. Bariatric surgery for individuals with a BMI less than $35 \mathrm{~kg} / \mathrm{m}^{2}$ with obesity related co-morbidities is under investigation but is not currently recommended [21].

If a candidate meets the criteria for surgery, then a multi-disciplinary team assessment is made as to the suitability of the candidate. This is a complex process involving psychological, surgical, dietetic and medical review. The individual must be physically and psychologically fit to proceed to surgery. Expectations must be managed and a determination must be made as to the individuals' ability to comply with post-operative care. The decision to operate will take into account the benefits the candidate is likely to gain, and the risks perioperatively and post-operatively.

This is an individualized assessment, and the role of the psychologist and/or psychiatrist should be central. Some reports suggest an increased risk of suicide after bariatric surgery, although the etiology remains unclear [6]. Major failures of bariatric surgery are due to poor psychological adaptation, especially if the patient's expectations were not adequately managed. All candidates should be given the correct and realistic information on what the procedure can achieve. If this is addressed, then the risk of surgical failure can often be mitigated [22,23]. This personalized assessment is a vital part of the pre-operative assessment.

For each patient the benefits of the procedure should outweigh the operative risk. In general, obese patients have an increased prevalence of cardiopulmonary disease that may be undiagnosed pre-operatively [24]. An individualized pre-operative assessment should be completed by a multi-disciplinary team [25]. Pre-operative investigations should focus on screening for cardiac arrhythmia, prolonged QT syndrome, and cardiomyopathy [25]. Almost 70\% of individuals awaiting bariatric surgery can be diagnosed with obstructive sleep apnea, with over $40 \%$ meeting the criteria for severe disease $[26,27]$. However, this is not associated with a greater rate of peri-operative complications [28]. Male gender, age older than 50 years, congestive heart failure, peripheral vascular disease and renal impairment are associated with greater mortality [29].

\section{Predicting outcomes}

Once the candidate has been selected, then the appropriate procedure must be chosen. Unfortunately, there is no evidence based medical approach for procedure selection, and this remains one of the most frustrating shortfalls in bariatric practice for clinicians and patients. Clinicians take a pragmatic approach to the choice of procedure, and the decision is determined by the individuals' clinical phenotype, the aims of therapy, and peri-operative risk.

Clinicians and patients can often be disappointed when surgical outcomes are not as impressive as may 


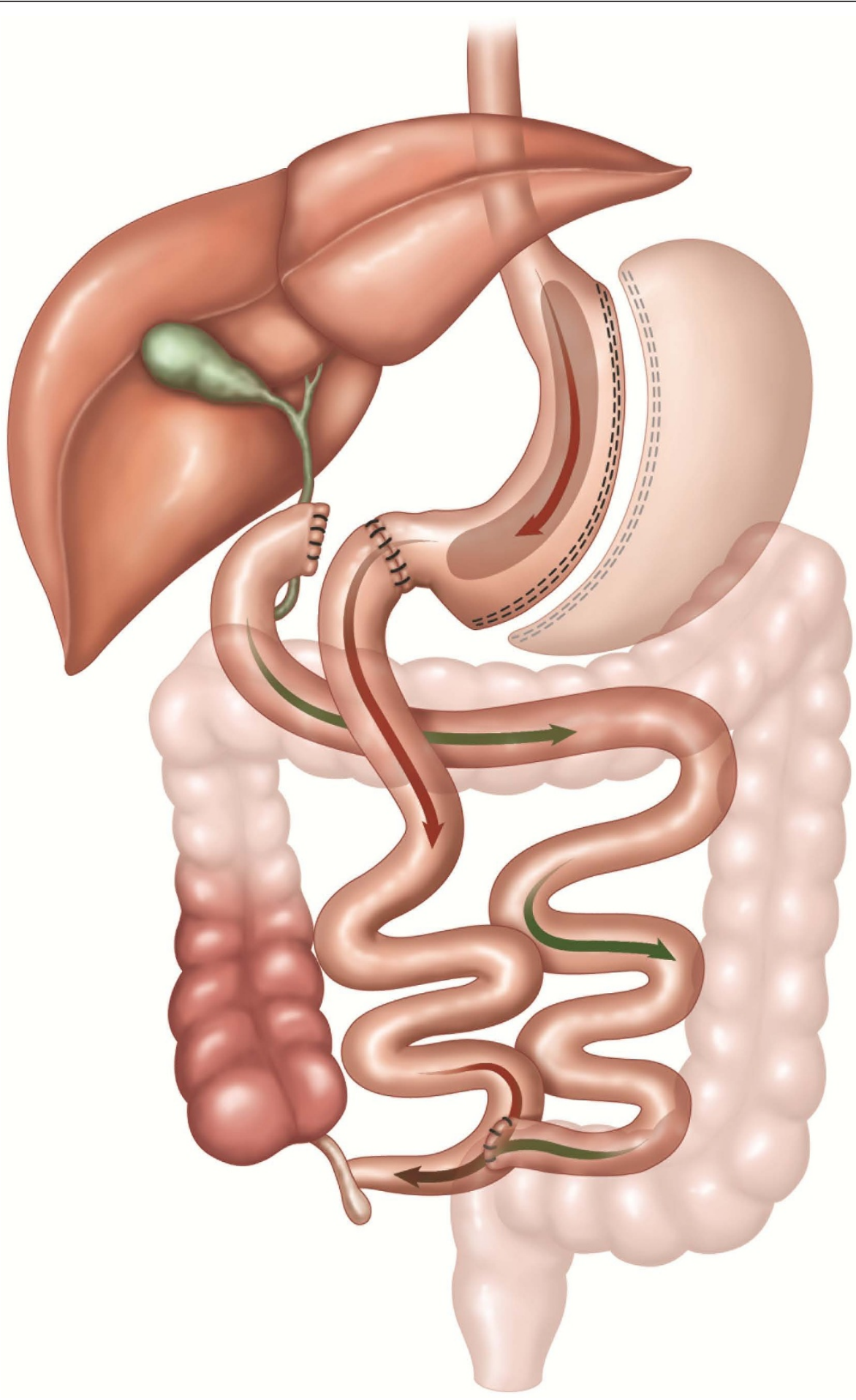

Figure 4 BPD: Biliopancreatic diversion. A $400 \mathrm{~mL}$ gastric pouch is formed from the stomach. The small bowel is divided $250 \mathrm{~cm}$ proximal to the ileocecal valve and is connected to the gastric pouch to create a Roux-en-Y gastroenterostomy. An anastomosis is performed between the excluded biliopancreatic limb and the alimentary limb $50 \mathrm{~cm}$ proximal to the ileocecal valve. In BPD-DS, a vertical sleeve gastrectomy is constructed and the division of the duodenum is performed immediately beyond the pylorus. The alimentary limb is connected to the duodenum, whereas the iliopancreatic limb is anastomosed to the ileum $75 \mathrm{~cm}$ proximal to the ileocecal valve. The included figures are the property of Johnson and Johnson and Ethicon Endo-Surgery (Europe). They are reproduced here with their kind permission. 
have been hoped and look for objective evidence that can allow them to predict outcomes. The most damaging outcome of surgical procedures that do not perform as expected is to blame the recipient for not performing well enough with regard to diet and exercise, when in fact, the failure is almost always rooted in biology. Weight loss prediction is one of the common aims of these predictive models. Pre-operative weight loss can predict post-operative weight loss, putatively as a marker of 'intrinsic motivation' [30,31]. These data are contentious and not without bias as many of them are retrospective uncontrolled studies [32]. The available prospective data are of short duration [31,32]. A systematic review shows that $50 \%$ of the published results find that pre-operative weight loss has an association with weight change post-operatively, and the remaining $50 \%$ refute these findings [32]. In the context of this evidence, pre-operative weight loss cannot be relied on to predict surgical outcomes at this time.

Genetic disorders such as melanocortin-4 receptor (MC4R) deficiency may have an inherent physiological role in these mixed results, as animals with MC4R deficiency have a resistance to weight loss after bariatric surgery [33]. There is interest in these genotypes, as identifying them may aid the prediction of outcomes. However, identified phenotypes such as MC4R are not common in the obese population, with heterogeneous mutations identified in less than 3\% of European and North American obese cohorts [34]. Culprit genes that have been associated with obesity, with approximately 20 implicated to date, are still only found in $5 \%$ of obese people [35].

Investigation of genetic factors that may predict individual responses to bariatric surgery is ongoing and controversial [35-37]. While certain genotypes are associated with improved outcomes after bariatric surgery, they are not procedure specific and, therefore, while potentially aiding prediction of weight loss post-operatively, will not aid procedure selection [35-37]. It is also well recognized that the genetic influence on obesity may be much more complex than we currently understand, with the inevitable influence of environment making the situation less clear. For now, study of identified genotypes, with a correlation between genotype and treatment outcomes, may answer questions on the clinical utility and predictive ability of genotyping in bariatric surgery [33].

To date, any potential genetic markers or biomarkers of weight loss following bariatric surgery have been limited by clinical utility, and sensitivity and specificity $[38,39]$. Some data identifying potential markers of weight loss are inadequately controlled and unmatched [38]. The positive findings are in the context of complex interactions, without clinically usable tests that could be applied in daily practice [39].
While there is some potential in this field, usable techniques are still many years away [40].

The factors most consistently negatively associated with post-operative weight loss include higher BMI levels and personality disorders [32]. Given the impact of psychological markers on outcomes, techniques such the artificial neural network, which can incorporate psychological and biological measurements, have been tested to predict surgical outcomes [41]. Such techniques rely on established data that have been shown to effect outcomes, but may incorrectly predict response in as many as $30 \%$ of bariatric surgery recipients [41]. These models are multi-factorial, prone to bias and socio-cultural differences [41]. They are also time-consuming and expensive [41]. As the techniques are refined, we may develop a useful model that could be employed in routine practice, although we have not arrived at that point as of yet.

While weight loss remains difficult to predict, there are increasing amounts of data on prediction of diabetes remission. Markers of insulin secretion, such as C-peptide may aid pre-operative prediction of diabetes remission [42]. These results report an increased rate of diabetes remission with higher $C$-peptide levels $[42,43]$. The highest cut-off can predict diabetes remission with a specificity of approximately 90\% [42]. Shorter duration of diabetes, lower glycosylated hemoglobin (HbA1c) levels and insulin independence are also associated with a higher post-operative remission rate $[43,44]$. These data illustrate a role for $\mathrm{C}$-peptide to be used in conjunction with clinical data to predict diabetes remission. If a validated, sensitive and specific model were developed then it may aid procedure selection. However, the models currently studied can provide great specificity, but only at the cost of sensitivity [45].

The use of incretin and bile acid profiles has been investigated for use in predicting weight loss and metabolic outcomes following bariatric surgery $[46,47]$. The findings suggest that the restoration of peptide YY (PYY) and glucagon-like-peptide- 1 (GLP-1) secretion following RYGB contribute to satiety and weight loss $[46,48]$. Bile acids also have a role in this process, and the mechanisms underlying this are currently being elucidated [47]. Increased bile acid delivery to the terminal ileum can improve satiety and enhance weight loss [47]. However, these changes occur after surgery, and there is no current evidence that would allow them to be used to select candidates pre-procedure.

Similarly, while the restoration of the PYY and GLP-1 response is associated with satiety and weight loss in RYGB, as opposed to AGB, there are no strong data on differences within this group that allow us to predict the degree of weight loss following RYGB based on the incretin or bile acid response $[48,49]$. There are data demonstrating a progressive rise in PYY and GLP-1 following 
RYGB that is associated with increased satiety but without noted differences within the group [49]. The relationship between absolute incretin or bile acid levels, or trends, and weight loss remains to be determined. At this time, the restoration of incretin secretion and increased serum levels of bile acid are associated with enhanced satiety and weight loss, but they cannot be used to predict weight loss [46-49].

\section{Procedure selection}

For now, procedure selection is best informed by the candidates' objectives and by how they want to live their lives after surgery. As a primary aim of surgery, the efficacy of weight loss associated with each procedure must be considered. RYGB results in greater weight loss than $A G B$, although good quality post-operative care can improve the weight loss following AGB, with results comparable to RYGB [50-52]. AGB is associated with a lower rate of immediate post-operative complications but also a higher rate of re-operation for insufficient weight loss [50-52]. The associated mortality rate is higher with RYGB than with AGB but still less than 0.3\% [50,51].

Weight loss is comparable between RYGB and SG in the short term $[53,54]$. Some studies suggest that more patients will regain weight in the medium-term after SG [55]. BPD/BPD-DS results in greater weight loss, but with higher complication rates, than RYGB $[56,57]$. Therefore, the greatest weight loss would likely be achieved with BPD/BPD-DS. However, this is not generally agreed. BPD/BPD-DS may not be suitable for highrisk operative candidates and some randomized controlled trials have shown no additional benefit of the extra weight loss above RYGB [58].

There are variances in outcome between national health systems, with AGB considered a superior bariatric procedure in systems where there is an excellent postoperative care pathway [52]. This implies that AGB can have comparable results providing that the post-operative care is planned and provided by experienced clinicians.

With regard to diabetes remission or treatment, RYGB offers a greater rate of remission than AGB [50,51]. SG has a remission rate comparable to RYGB in the shortterm, but a higher rate of relapse in the medium-term [59]. BPD and BPD-DS may offer a higher rate of diabetes remission than RYGB or AGB [60-62]. While AGB is the least effective in inducing diabetes remission, it can offer substantial improvements in diabetes control, which are greater than those offered by medical therapy in obese cohorts $[63,64]$.

Other conditions can influence a decision on bariatric surgery. Respiratory disease may improve more significantly with greater weight loss [65]. Therefore, those with obstructive sleep apnea (OSA) or asthma could theoretically be considered for more consistently efficacious procedures such as BPD/BPD-DS or RYGB. Conversely, SG and AGB are associated with deteriorations in gastroesophageal reflux disease (GERD) and, therefore, should be avoided in this cohort $[55,66]$. In GERD, RYGB is increasingly considered as the treatment of choice as it can remediate the GERD due to the reduction in the stomach pouch and prevention of esophageal reflux [67]

In summary, candidate selection and preparation is key to achieving good surgical outcomes. Each procedure should be considered for each individual, and the data to date do not support the application of a generic selection based on body weight, diabetes or other co-morbidities. The choice of procedure is a complex process with the patient and their interests at its core. The surgeon's experience to deal with the inevitable complications of each procedure and to manage long-term follow-up care remain dominant considerations.

In those with diabetes, $\mathrm{BPD} / \mathrm{BPD}-\mathrm{DS}$ offers the highest rate of remission, but also the highest complication rates. RYGB and SG are comparably efficacious in treating diabetes in the short-term, but questions remain regarding the medium to long-term. It should be noted that the volume of data for RYGB is greater than that for SG and BPD/BPD-DS. For those with GERD, RYGB should be the treatment of choice. SG and AGB should be avoided.

AGB can also lead to weight loss and diabetes remission and can offer greater control than medical therapy, even if remission is not achieved. It should be noted that the choice of AGB should take into account the availability of good quality post-operative care. AGB may be suitable for those who wish to lose weight and improve diabetes control, but not remission, and are at higher surgical risk.

\section{Clinical outcomes}

The outcomes following bariatric surgery vary between procedures, and predicting individual outcomes following bariatric surgery is difficult, for the reasons outlined in the previous sub-sections. We will review each outcome individually and compare between modalities below.

\section{A. Airway: Obstructive sleep apnea (OSA) and asthma}

Bariatric surgery is associated with impressive remission rates for OSA (68). However, bariatric surgery can improve the severity of OSA more frequently than resulting in full remission, and the improvement can still leave the individual in a moderate or severe category [68]. The symptoms of asthma can improve after bariatric surgery but the mechanism of this effect is unknown, although reduction of subcutaneous tissue with improvement of the restrictive effect on the chest wall may be involved [69].

\section{B. Body weight}

Bariatric surgery effectively induces weight loss, but the degree varies between procedures [8-10]. RYGB results in greater weight loss than AGB in most studies [51]. The quality of the post-operative care affects weight loss after 
AGB, with good quality post-operative care resulting in comparable weight loss to RYGB [52]. Weight loss is comparable between RYGB and SG at 36 months postoperatively but long-term data are pending [53]. Weight regain can be frequent following SG [55]. BPD results in greater weight loss, but higher complication rates, than RYGB, with comparable metabolic and quality of life outcomes $[56,58]$.

Weight loss usually reaches a maximum twelve months post-operatively, and some weight regain is common thereafter. The mean ten-year weight reduction is $25 \%$ for RYGB and $13 \%$ for AGB [4].

\section{Cardiovascular and cardiac disease}

Obesity is a risk factor for cardiovascular disease [70]. The available data over a median of almost twenty years show that bariatric surgery is associated with reduced cardiovascular mortality and morbidity [71]. In RYGB a reduction of cardiovascular morbidity of more than $50 \%$ is seen when compared to BMI and age matched controls $[6,71]$. The mechanism is unclear but improvements in glucose metabolism, blood lipid profiles and hypertension probably contribute $[71,72]$. The reduction in hypertension and dyslipidemia does remit somewhat post-operatively but both remain reduced from baseline at ten years [6,7].

Cardiomyopathy in obesity is associated with left ventricular hypertrophy and diastolic dysfunction with a longer exposure to obesity associated with worse cardiac function and larger ventricular mass [73]. Left atrial dilatation and systolic dysfunction can also develop [74]. This is likely due to a combination of increased cardiac output and increased circulatory volume [74]. Bariatric surgery has been shown to result in improved cardiac function and 'reverse remodeling' of the left ventricle up to three years post-operatively [75].

\section{Diabetes}

There is a strong association between obesity and diabetes with approximately half of those diagnosed with T2DM classified as obese [76]. Bariatric surgery can induce remission of diabetes by inducing weight loss [61]. There are also enteroendocrine effects following RYGB and BPD, achieving greater remission rates for diabetes when compared to patients who have had similar weight loss after AGB [61]. Diabetes remission is greatest for patients undergoing BPD-DS, followed by RYGB and then AGB [61]. SG has a comparable remission rate to RYGB $[59,77]$. The remission of diabetes following bariatric surgery can be transient, with $72 \%$ free of diabetes two years after bariatric surgery but only $36 \%$ remaining free of diabetes at ten years [4].

The most reliable long-term prospective data comes from the Swedish Obese Study in which the majority of participants underwent vertical banded gastroplasty with the remaining undergoing RYGB or AGB [4]. Subgroup analyses report that the RYGB group $(\mathrm{N}=34)$ had a greater reduction in serum glucose at ten years than the rest of the cohort $(\mathrm{N}=608)$ [4]. However, rates of diabetes according to subgroup and other prospective data for RYGB specifically are not available. Retrospective data at nine years following RYGB show a reduced rate of medical treatment of diabetes by more than $65 \%$ in parallel with a reduction in mortality of more than $70 \%$ [78]. The improvement in mortality was primarily due to a decrease in the number of cardiovascular deaths.

Shorter duration of diabetes, lower HbA1c levels and insulin independence are associated with a higher postoperative remission rate [44].

The presence of diabetes could influence the choice of bariatric procedure with RYGB, BPD and SG considered to result in remission of diabetes in a significant proportion of candidates. In those who do not achieve remission, bariatric surgery, including AGB, results in better glycemic control and a reduced medication burden compared to medical treatment $[63,64]$. Emerging data also suggest that bariatric surgery may facilitate remission of microvascular complications, such as microalbuminuria [79].

\section{E. Economic}

Obese individuals are more than twice as likely to take sick leave and almost three times as likely to avail of disability benefits [4]. Medical costs are significantly higher for obese individuals, mainly due to the cost of diabetic, hypertensive and lipid therapy, but with additional costs secondary to analgesia, respiratory and psychiatric treatments [80,81]. When classified by BMI, patients in the highest ranges spend more on healthcare [81].

While the presence of obesity may be secondary to lower socio-economic status rather than causative, bariatric surgery has been shown to result in increased productivity and reduced sick leave [82,83]. It is more costly than non-surgical management of obesity in the shortterm but a return of investment can be achieved within four years [84].

Medication prescription is reduced by bariatric surgery with resultant reductions in healthcare costs that can persist for up to 20 years $[84,85]$. Cost effectiveness may also be achieved through reduced healthcare system utility due to the reduction in obesity related co-morbidities [85]. However, the modeling used in this type of cost assessment is open to criticism and there is a dearth of controlled prospective data.

\section{F. Functional}

Basic activities of daily living such as walking and personal hygiene can be affected by severe obesity, and this loss of autonomy can be extremely distressing for the affected individuals [86]. Joint pain, including lower back pain, is common in obese populations and can impinge on individual functional status [87]. Bariatric surgery results in improved function status, reduced levels of back pain and greater levels of independence [87]. 


\section{G. Gonadal function and fertility}

In men, obesity can result in erectile dysfunction, reduced serum testosterone levels and reduced sperm quality $[88,89]$. Bariatric surgery is associated with increased serum testosterone levels but may paradoxically result in a deterioration in sperm quality $[90,91]$. There are no controlled prospective data to evaluate the effect of bariatric surgery on male fertility.

In women, obesity is associated with high rates of ovulatory dysfunction, increased risk of spontaneous abortion and increased materno-fetal risk in pregnancy [92]. There is evidence that weight reduction via bariatric surgery can improve ovulatory cycles and reduce hyperandrogenism in women [93]. It also probably reduces materno-fetal risk, although the current evidence is mainly limited to observational data $[94,95]$. To date, there are no randomized controlled data or long-term prospective data available and, therefore, no strong recommendation can be made on advising reproductively active women considering bariatric surgery.

\section{H. Perceived health status}

People who are classified as obese often report poor health perceptions and altered mood [96]. Psychiatric co-morbidities including anxiety and depression are also common [97]. Bariatric surgery improves quality of life and perceived health status, with changes seen in the first year and benefit retained up to ten years [96]. Depression, aggression and low self-concept can all be improved by bariatric surgery [97]. The improvements in perceived health status and quality of life may be correlated with weight loss, with superior results following RYGB compared to AGB [98]. However, factors other than weight loss may be responsible for these psychological benefits as the improvements have been reported in the immediate post-surgical phase [99].

\section{Image}

Body image dysphoria is found in high frequency in obese cohorts but this sometimes improves post-operatively $[86,100]$. The improvement in body image satisfaction is associated with improved quality of life scores, and the improvements continue for at least two years following surgery $[101,102]$. Weight regain is associated with deterioration in self-concept and body image and can be associated with depressive symptoms [102]. In general, changes in body image are very unpredictable.

Eating disorders are common in obese populations [101]. Some evidence suggests that bariatric surgery can be associated with remission of eating disorders, particularly binge eating disorder [103]. The persistence of these disorders is associated with poor outcomes, and eating behavior needs to be regularly reviewed post-operatively [103].

\section{J. Junction of gastro-esophagus}

The presence of obesity and GERD has been linked with pre-malignant metaplasia of the gastro-esophageal junction, and frank adenocarcinoma of the esophagus [104]. RYGB can reduce the symptoms of GERD and is associated with regression of pre- malignant metaplasia $[67,105]$. There is concern that AGB may worsen symptoms in a significant proportion of recipients [66]. SG has also been associated with worsening GERD, and patients with pre-existing disease may not be suitable candidates [55].

Surgical treatment of GERD can be ineffective in obese populations, and RYGB can be considered before fundoplication in this group given the improved outcomes [67]. Therefore, the presence of GERD supports use of RYGB as a first line procedure.

\section{K. Kidney function}

While the measurement of glomerular filtration rate in obese cohorts is not well validated, obesity is noted to result in higher rates of chronic kidney disease (CKD) independent of the effect of co-morbid diabetes mellitus, hypertension or dyslipidemia [106,107]. Renal parameters such as serum creatinine and urinary protein excretion can improve after bariatric surgery, but at present it is unknown if the potential benefits outweigh the risks in those with CKD, given the greater peri-operative risk associated with renal impairment $[29,108,109]$.

\section{Liver}

Liver disease such as hepatosteatosis, non-alcoholic steatohepatitis (NASH), hepatic fibrosis, and cirrhosis are all associated with obesity [110]. Bariatric surgery improves the histological appearance of the liver and can lead to regression of established liver disease [111]. However, these data are often uncontrolled and some authors have reported worsening in fibrosis rates after bariatric surgery [111]. The presence of fibrotic liver disease needs to be considered in the decision to proceed with surgery and in follow-up plans post-operatively.

\section{Medication}

Bariatric surgery results in a significant cost reduction in glycemic, lipid and antihypertensive therapy that can take effect within two weeks of surgery $[84,85]$. There are additional therapies needed following bariatric surgery, with increased prescription of GERD therapy with some procedures [80]. The need for increased GERD treatment and ongoing mineral and vitamin supplementation can partially offset the cost reductions in diabetic and cardiovascular medication $[80,85]$.

\section{O. Other}

There is emerging evidence that weight loss using bariatric surgery may reduce the incidence of cancer [112]. It seems that the protective effect is strongest for women, and the reduction of risk may be as high as $60 \%$ $[6,112,113]$. The mechanisms underlying this apparent risk reduction are unclear, but may involve mediation of inflammatory pathways and attenuation of obesity associated hyperinsulinism [112]. 


\section{Morbidity and mortality after bariatric surgery}

Surgical complications can be defined as early or late, depending on if they occur within the first thirty postoperative days or afterwards. There is a wide range in the reported complication rates. The benchmark for bariatric centers of excellence is the Longitudinal Assessment of Bariatric Surgery consortium [114]. Mortality rates after bariatric surgery are low with a mortality rate after RYGB of $0.3 \%$ [114]. Pulmonary and venous thrombo-embolism are early complications and occur in less than $0.5 \%$ of bariatric surgery recipients [115]. Other complications can be specific to the modality and include the following.

\section{Anastomotic leak and bowel perforation}

Anastomotic leak is a feared early complication. Higher BMI, male gender, re-operation, older age and surgeon's experience are all associated with higher rates of anastomotic leakage $[115,116]$. Leakage can occur at any of the anastomotic junctions in RYGB, SG or BPD/BPD-DS and can result in severe peritonitis, sepsis, and multi-organ failure. Enteric leaks require emergent operative treatment in the context of hemodynamic instability or peritonitis.

Anastomotic leakage appears most commonly at the gastrojejunostomy in RYGB and the incidence associated with mortality is $0.1 \%[116,117]$. The incidence of leakage is up to $3.6 \%$ in SG and most commonly occurs as a defect in the staple line [118]. In BPD-DS, leakage from the staple line is more common than anastomotic leakage and the total enteric leakage rate is 5\% [119].

In AGB, there is no anastomosis and gastro-esophageal perforation is an uncommon early complication that can result in peritonitis and abdominal sepsis with an incidence of less than $0.5 \%$ [120].

\section{Hemorrhage}

Hemorrhage is an early complication that occurs in up to $4 \%$ of patients [121]. Using finer anastomotic closure techniques can reduce bleeding rates [122]. The presence of diabetes mellitus has been associated with a higher risk of post-operative hemorrhage [123]. In SG, hemorrhage has an incidence of up to $5.6 \%$, but there is a large range in reported data that is likely explained by surgical experience, the complexity of the case intra-operatively, and the use of buttress material [124,125].

\section{Bowel obstruction}

Internal hernias can cause bowel obstruction, and can occur early or late post-operatively. The reported frequency ranges from $0.4 \%$ to $5.5 \%$ in RYGB $[126,127]$. Long-term data over seven years record a hernia rate of $38 \%$ in BPD/BPD-DS [128]. A laparoscopic approach may result in higher rates, but new surgical techniques where the mesentery windows are surgically closed may reduce the rate to as low as $1 \%$ [129].

\section{Anastomotic stricture}

Anastomotic stricture is a late complication that can occur at any of the anastomotic sites. It is commonly described at the gastrojejunostomy in RYGB and is associated with dysphagia and vomiting [130]. The mean incidence of gastrojejunal stricture is approximately $10 \%$, but rates as high as $20 \%$ are reported [130]. The laparoscopic approach and use of circular staplers to make the gastrojejunal anastomosis may result in higher rates of stricture [131].

\section{Other complications}

Incisional hernias can occur but are less common with the increased use of laparoscopic techniques [10]. Marginal ulcers are usually late complications of bariatric surgery and occur in $2 \%$ of patients within the first post-operative year, and then in $0.5 \%$ for up to five years [132]. Proton pump inhibition is the preferred treatment but ulcers can be refractory and may require revisional surgery [133].

\section{Complications specific to $A G B$}

Band migration is becoming less common since the introduction of the 'pars flaccida' technique and individually sized bands, with rates as low as 1.4\% [134]. Band migration can result in acute postoperative stoma obstruction, although this can occur in the absence of migration due to impacted food boluses [135].

Infections of the adjustment port can be an early or late complication. A late adjustment port infection can present years post-operatively, with abdominal pain or port site erythema, caused by band erosion with ascending infection, in up to $1 \%$ of cases [136]. This can result in intraabdominal sepsis requiring removal of the band and high dose intravenous antibiotics. Band erosion is associated with surgical experience, with higher rates in those with less experience [137].

There is a recognition that AGB can have high failure rates in long-term follow-up, although this can likely be remediated by good quality post-operative care $[138,139]$. The emergence of SG as a procedure with greater weight loss and metabolic effects than AGB, with complication rates comparable or possibly slightly lower than RYGB has led to the consideration of SG before AGB in some cases [139]. However, SG's major Achilles heel is the lack of longterm data with some authors concerned that the 10-year reoperation rate after SG will be similar to that of AGB.

As long-term data accumulate, SG may come to replace $A G B$ in many cases, although for now AGB is likely to remain more popular given the established experience in its use and the lower complication rate in comparison to the other major bariatric modalities [139].

\section{Nutritional and gastrointestinal complications after bariatric surgery}

Deficiencies of iron, vitamin B12, folate, and fat-soluble vitamins can occur after bariatric surgery and are best 
described in RYGB, BPD and BPD-DS [140]. Vitamin D deficiency can persist despite prescribed replacement in BPD and may tend towards secondary hyperparathyroidism [140]. The risk of nutritional deficiencies depends on postoperative weight loss, the surgical procedure performed and patient compliance with follow up [140,141].

Vomiting is frequent after bariatric surgery but must always be considered to be pathological until proven otherwise after RYGB. An examination and appropriate radiological studies to screen for stricture, stoma stenosis or herniation must be completed. If no pathological cause is found then treatment should be conservative with replacement of fluid and electrolytes [141]. Often, vomiting can be the result of overeating or rapid eating. The patient should be re-educated on eating habits and kept under review.

Diarrhea is reported in up to $40 \%$ following bariatric surgery [142]. More than $30 \%$ of bariatric surgical recipients report worsening bowel function in the post-operative period and some develop fecal incontinence [143]. The etiology of this is unclear and treatment is based on appropriate dietary modification and anti-diarrheal pharmacotherapy.

There is a variable incidence of the dumping syndrome after bariatric surgery, particularly in RYGB [144]. Dumping syndrome remains a 'waste-basket diagnosis', with the clinical presentation generally considered to include early abdominal pain, diarrhea, nausea, bloating, fatigue, facial flushing, palpitations, hypotension and syncope after high glycemic index meals. These symptoms usually occur within an hour of eating. Similar symptoms that occur two or three hours after a meal include perspiration, palpitations, hunger, tremor, agitation, and syncope [144]. These have been blamed on hypoglycemia and GLP-1, although a definitive etiology remains to be established [145,146].

The treatment of early dumping syndrome is usually straightforward dietary modification, with small regular meals containing protein and carbohydrate with a very low glycemic index. Treatment of the symptoms that occur within two or three hours of a meal also rely on the same dietary modifications, with the added aim of 2 or 3 $\mathrm{kg}$ of weight gain which often abolishes the symptoms secondary to the small amount of increased insulin resistance. Pharmacotherapy with acarbose or somatostatin analogues may be needed [147], with transient enteral feeding required in severe cases [144].

There is some overlap in the hypoglycemic syndromes associated with bariatric surgery, with a number of mechanisms likely contributing to each. Obesity-related beta-cell hypertrophy that does not fully regress after weight loss, with improved GLP-1 dynamics and improved peripheral sensitivity, all probably contribute to each syndrome [148]. There can be an exaggerated incretin response in those with hypoglycemic syndromes $[145,146]$. However, the extent to which the incretin effect is involved can vary by syndrome and even by case [148]. If a post-operative patient presents with dumping syndrome or hypoglycemia that is unresponsive to dietary modification or $3 \mathrm{~kg}$ weight gain, or with atypical features such as fasting symptoms, then a full investigation of their insulin dynamics is needed.

\section{Other complications after bariatric surgery}

Other post-operative complications include alopecia, cholelithiasis and hypoglycemia. Postoperative hair loss has been reported in up to $4.5 \%$ of bariatric surgical candidates [149]. This is usually mild and non-progressive. Cholelithiasis can occur in up to $2 \%$ of individuals in the months after surgery [150]. Ursodeoxycholic acid has been recommended for prevention [140].

\section{Future directions}

As obesity continues to become more prevalent, bariatric surgery will become necessary for greater numbers of people. The current guidelines are aimed at a grade of obesity considered moderate to severe, but evidence is accumulating for the use of bariatric surgery in those with BMI levels of less than $35 \mathrm{~kg} / \mathrm{m}^{2}$ [151]. This is particularly the case in those with diabetes [151].

The ongoing randomized controlled trials comparing bariatric surgery and intensive medical glycemic therapy may yield results that will lead to bariatric surgery being used for metabolic benefits in those with diabetes, including those with BMIs of less than $35 \mathrm{~kg} / \mathrm{m}^{2}$ $[63,64]$. This is the continuation of the concept of metabolic surgery; the idea that bariatric procedures should have a primary goal of inducing remission of metabolic diseases, such as diabetes. However, this concept remains controversial, and further data need to be collected to determine the benefits of this approach.

Finally, the goal of individualizing bariatric treatment and predicting response remains challenging. The work on genotyping and predictive models is ongoing but usable models remain elusive. Evidence to date suggests that the factors most predictive of weight loss may be psychological [32]. As genome association data are gathered we may identify genes that can allow us to tailor the bariatric approach to the individual $[36,37,152,153]$. However, given the expense associated with this technology, its clinical utility at present is low and clinical evaluation will remain the mainstay of pre-operative assessment and procedure selection.

\section{Conclusions}

Bariatric surgery should be considered in individuals with a BMI of greater than $40 \mathrm{~kg} / \mathrm{m}^{2}$ and in those with a BMI of more than $35 \mathrm{~kg} / \mathrm{m}^{2}$ and obesity related co- 
morbidities. In future, guidelines may recommend surgery for those with BMIs of less than $35 \mathrm{~kg} / \mathrm{m}^{2}$ with diabetes or other metabolic disease.

Not all candidates are suitable to proceed to surgery, and an experienced multi- disciplinary assessment is essential to select the appropriate candidates. The choice of surgical modality should take the individual's goals, surgeon's experience and existing co-morbidities into account. Individualizing care is central to the assessment, and this is determined by clinical evaluation rather than using predictive models, genotyping or biomarkers at present.

Bariatric surgery performed in experienced centers has a low complication rate and leads to long-term weight loss, with associated functional, metabolic and psychological improvements. Bariatric procedures are effective in treating and preventing many obesity related co-morbidities. Longterm follow-up is mandatory to support a safe outcome.

\section{Abbreviations \\ AGB: adjustable gastric banding; BMl: body mass index; BPD: biliopancreatic diversion; BPD-DS: biliopancreatic diversion with duodenal switch; GERD: Gastro-esophageal reflux disease; GLP-1: glucagon-like peptide 1; HbA1c: glycosylated hemoglobin; OSA: obstructive sleep apnea syndrome; RYGB: Roux-en-Y gastric bypass; SG: sleeve gastrectomy; T2DM: type 2 diabetes mellitus.}

\section{Authors' contributions}

KJN reviewed the published literature for this review and drafted the manuscript. TO contributed to the content and structure of the article and, in particular, to the sections on surgical technique and complications. CWleR was invited to submit this review, and conceived the design and structure of the article. All authors edited, read and approved the final manuscript.

\section{Authors' information}

$\mathrm{KJN}$ is a research fellow in metabolic medicine and has a clinical background in endocrinology and diabetes. His special interests include obesity and the metabolic effects of bariatric surgery, and the effects of the incretin system in obesity and diabetes.

CleR is the Professor of Experimental Pathology at University College Dublin with a special interest in the mechanisms and clinical application of bariatric surgery. His work has focused on how the operations allow long-term weight loss maintenance and metabolic benefit.

TO is a specialist bariatric surgeon who has performed more than 3,000 bariatric procedures. His practice is focused on laparoscopic gastric bypass, sleeve gastrectomy and duodenal switches. He completed his PhD at Sahlgrenska University Hospital in Sweden, and then became the director of the bariatric surgical unit at Carlanderska Hospital in Gothenburg. He is currently leader of a research group in the field of mechanisms and impact of bariatric surgery.

\section{Competing interests}

The authors declare that they have no competing interests.

\section{Author details}

'Experimental Pathology, UCD Conway Institute, School of Medicine and Medical Sciences, University College Dublin, Belfield, Dublin 4, Dublin, Ireland. 'Department of Bariatric Surgery, Carlanderska Hospital, Gothenburg, Sweden. ${ }^{3}$ Department of Gastrosurgical Research and Education, University of Gothenburg, 5-413 45 Gothenburg, Sweden.

Received: 13 April 2012 Accepted: 10 January 2013 Published: 10 January 2013

\section{References}

1. World Health Organization: Global Strategy on Diet, Physical Activity and Health. Geneva, Switzerland; 2011, [updated June 2012]; Available from: [http://www.who.int/dietphysicalactivity/publications/obesity/en/index.html].

2. Yan LL, Daviglus ML, Liu K, Stamler J, Wang R, Pirzada A, Garside DB, Dyer AR, Van Horn L, Liao Y, Fries JF, Greenland P: Midlife body mass index and hospitalization and mortality in older age. JAMA 2006, 295:190-198

3. Vlad I: Obesity costs UK economy 2 bn pounds sterling a year. BMJ 2003, 327:1308.

4. Sjostrom L, Lindroos AK, Peltonen M, Torgerson J, Bouchard C, Carlsson B, Dahlgren S, Larsson B, Narbro K, Sjostrom CD, Sullivan M, Wedel H, Swedish Obese Study Scientific Group: Lifestyle, diabetes, and cardiovascular risk factors 10 years after bariatric surgery. N Engl J Med 2004, 351:2683-2693.

5. O'Brien PE, Dixon JB, Laurie C, Skinner S, Proietto J, McNeil J, Strauss B, Marks S, Schachter L, Chapman L, Anderson M: Treatment of mild to moderate obesity with laparoscopic adjustable gastric banding or an intensive medical program: a randomized trial. Ann Intern Med 2006, 144:625-633

6. Adams TD, Gress RE, Smith SC, Halverson RC, Simper SC, Rosamond WD, Lamonte MJ, Stroup AM, Hunt SC: Long-term mortality after gastric bypass surgery. N Engl J Med 2007, 357:753-761.

7. Sjostrom L, Narbro K, Sjostrom CD, Karason K, Larsson B, Wedel H, Lystig T, Sullivan M, Bouchard C, Carlsson B, Bengtsson C, Dahlgren S, Gummesson A, Jacobson P, Karlsson J, Lindroos AK, Lönroth H, Näslund I, Olbers T, Stenlöf K, Torgerson J, Agren G, Carlsson LM, Swedish Obese Subjects Study: Effects of bariatric surgery on mortality in Swedish obese subjects. N Engl J Med 2007, 357:741-752.

8. Buchwald H, Oien DM: Metabolic/bariatric surgery worldwide 2008. Obes Surg 2009, 19:1605-1611.

9. Smith BR, Schauer P, Nguyen NT: Surgical approaches to the treatment of obesity: bariatric surgery. Med Clin North Am 2011, 95:1009-1030.

10. Reoch J, Mottillo S, Shimony A, Filion KB, Christou NV, Joseph L, Poirier P, Eisenberg MJ: Safety of laparoscopic vs open bariatric surgery: a systematic review and meta-analysis. Arch Surg 2011, 146:1314-1322.

11. O'Brien PE, Dixon JB, Laurie C, Anderson M: A prospective randomized trial of placement of the laparoscopic adjustable gastric band: comparison of the perigastric and pars flaccida pathways. Obes Surg 2005, 15:820-826.

12. Scott WR, Batterham RL: Roux-en-Y gastric bypass and laparoscopic sleeve gastrectomy: understanding weight loss and improvements in type 2 diabetes after bariatric surgery. Am J Physiol Regul Integr Comp Physiol 2011, 301:R15-27.

13. Scopinaro N, Gianetta E, Pandolfo N, Anfossi A, Berretti B, Bachi V: [Bilio pancreatic bypass. Proposal and preliminary experimental study of a new type of operation for the functional surgical treatment of obesity]. Minerva Chir 1976, 31:560-566.

14. Hess DS, Hess DW: Biliopancreatic diversion with a duodenal switch. Obes Surg 1998, 8:267-282.

15. Gersin KS, Rothstein RI, Rosenthal RJ, Stefanidis D, Deal SE, Kuwada TS, Laycock W, Adrales G, Vassiliou M, Szomstein S, Heller S, Joyce AM, Heiss F, Nepomnayshy D: Open-label, sham-controlled trial of an endoscopic duodenojejunal bypass liner for preoperative weight loss in bariatric surgery candidates. Gastrointest Endosc 2010, 71:976-982.

16. Espinet-Coll E, Nebreda-Duran J, Gomez-Valero JA, Munoz-Navas M, PujolGebelli J, Vila-Lolo C, Martinez-Gomez A, Juan-Creix-Comamaia A: Current endoscopic techniques in the treatment of obesity. Rev Esp Enferm Dig 2012, 104:72-87.

17. Tarnoff M, Rodriguez L, Escalona A, Ramos A, Neto M, Alamo M, Reyes E, Pimentel F, Ibanez L: Open label, prospective, randomized controlled trial of an endoscopic duodenal-jejunal bypass sleeve versus low calorie diet for pre-operative weight loss in bariatric surgery. Surg Endosc 2009, 23:650-656

18. Schouten R, Rijs CS, Bouvy ND, Hameeteman W, Koek GH, Janssen IM Greve JW: A multicenter, randomized efficacy study of the EndoBarrier Gastrointestinal Liner for presurgical weight loss prior to bariatric surgery. Ann Surg 2010, 251:236-243.

19. Centre for Public Health Excellence at NICE (UK), National Collaborating Centre for Primary Care (UK): Obesity: The Prevention, Identification, Assessment and Management of Overweight and Obesity in Adults and Children. London 2006. 
20. NIH Consensus Development Conference Panel: Gastrointestinal surgery for severe obesity. Ann Intern Med 1991, 115:956-961.

21. Serrot FJ, Dorman RB, Miller CJ, Slusarek B, Sampson B, Sick BT, Leslie DB, Buchwald $H$, Ikramuddin S: Comparative effectiveness of bariatric surgery and nonsurgical therapy in adults with type 2 diabetes mellitus and body mass index $<35 \mathrm{~kg} / \mathrm{m} 2$. Surgery 2011, 150:684-691.

22. Ogden J, Avenell S, Ellis G: Negotiating control: patients' experiences of unsuccessful weight-loss surgery. Psychol Health 2011, 26:949-964.

23. Saltzman E, Anderson W, Apovian CM, Boulton H, Chamberlain A, CullumDugan D, Cummings S, Hatchigian E, Hodges B, Keroack CR, Pettus M, Thomason P, Veglia L, Young LS: Criteria for patient selection and multidisciplinary evaluation and treatment of the weight loss surgery patient. Obes Res 2005, 13:234-243.

24. Catheline JM, Bihan H, Le Quang T, Sadoun D, Charniot JC, Onnen I, Fournier JL, Bénichou J, Cohen R: Preoperative cardiac and pulmonary assessment in bariatric surgery. Obes Surg 2008, 18:271-277.

25. Association of Anaesthetists of Great Britain and Ireland: Peri-operative Management of the Morbidly Obese Patient. London 2007, [cited 12 June 2012]; [http://www.aagbi.org/publications/guidelines/docs/Obesity07. pdf].

26. Ravesloot MJ, van Maanen JP, Hilgevoord AA, van Wagensveld BA, de Vrie N: Obstructive sleep apnea is underrecognized and underdiagnosed in patients undergoing bariatric surgery. Eur Arch Otorhinolaryngol 2012, 269:1865-1871

27. Carneiro G, Florio RT, Zanella MT, Pradella-Hallinan M, Ribeiro-Filho FF, Tufik S, Togeiro SM: Is mandatory screening for obstructive sleep apnea with polysomnography in all severely obese patients indicated? Sleep Breath 2012, 16:163-168.

28. Weingarten TN, Flores AS, McKenzie JA, Nguyen LT, Robinson WB, Kinney TM, Siems BT, Wenzel PJ, Sarr MG, Marienau MS, Schroeder DR, Olson EJ, Morgenthaler TI, Warner DO, Sprung J: Obstructive sleep apnoea and perioperative complications in bariatric patients. Br J Anaesth 2011, 106:131-139.

29. Nguyen NT, Masoomi H, Laugenour K, Sanaiha $Y$, Reavis KM, Mills SD Stamos MJ: Predictive factors of mortality in bariatric surgery: data from the Nationwide Inpatient Sample. Surgery 2011, 150:347-351.

30. Alvarado R, Alami RS, Hsu G, Safadi BY, Sanchez BR, Morton JM, Curet MJ: The impact of preoperative weight loss in patients undergoing laparoscopic Roux- en-Y gastric bypass. Obes Surg 2005, 15:1282-1286

31. Alami RS, Morton JM, Schuster R, Lie J, Sanchez BR, Peters A, Curet MJ: Is there a benefit to preoperative weight loss in gastric bypass patients? A prospective randomized trial. Surg Obes Relat Dis 2007, 3:141-145, discussion 5-6.

32. Livhits M, Mercado C, Yermilov I, Parikh JA, Dutson E, Mehran A, Ko CY, Meehan MM: Preoperative predictors of weight loss following bariatric surgery: systematic review. Obes Surg 2012, 22:70-89.

33. Mul JD, Begg DP, Alsters SI, van Haaften G, Duran KJ, D'Alessio DA, le Roux CW, Woods SC, Sandoval DA, Blakemore Al, Cuppen E, van Haelst MM, Seeley RJ: Effect of vertical sleeve gastrectomy in melanocortin receptor 4-deficient rats. Am J Physiol Endocrinol Metab 2012, 303:E103-110.

34. Calton MA, Ersoy BA, Zhang S, Kane JP, Malloy MJ, Pullinger CR, Bromberg Y, Pennacchio LA, Dent R, McPherson R, Ahituv N, Vaisse C: Association of functionally significant Melanocortin-4 but not Melanocortin-3 receptor mutations with severe adult obesity in a large North American case- control study. Hum Mol Genet 2009, 18:1140-1147.

35. Ranadive SA, Vaisse C: Lessons from extreme human obesity: monogenic disorders. Endocrinol Metab Clin North Am 2008, 37:733-751.

36. Sarzynski MA, Jacobson P, Rankinen T, Carlsson B, Sjostrom L, Bouchard C, Carlsson LM: Associations of markers in 11 obesity candidate genes with maximal weight loss and weight regain in the SOS bariatric surgery cases. Int J Obes (Lond) 2011, 35:676-683.

37. Liou TH, Chen HH, Wang W, Wu SF, Lee YC, Yang WS, Lee WJ: ESR1, FTO, and UCP2 genes interact with bariatric surgery affecting weight loss and glycemic control in severely obese patients. Obes Surg 2011, 21:1758-1765.

38. Harvey SB, Zhang Y, Wilson-Grady J, Monkkonen T, Nelsestuen GL, Kasthuri RS, Verneris MR, Lund TC, Ely EW, Bernard GR, Zeisler $H$ Homoncik M, Jilma B, Swan T, Kellogg TA: O-glycoside biomarker of apolipoprotein C3: responsiveness to obesity, bariatric surgery, and therapy with metformin, to chronic or severe liver disease and to mortality in severe sepsis and graft vs host disease. J Proteome Res 2009, 8:603-612.

39. Kim K, Perroud B, Espinal G, Kachinskas D, Austrheim-Smith I, Wolfe BM, Warden $\mathrm{CH}$ : Genes and networks expressed in perioperative omental adipose tissue are correlated with weight loss from Roux-en-Y gastric bypass. Int J Obes (Lond) 2008, 32:1395-1406.

40. Kim K, Zakharkin SO, Allison DB: Expectations, validity, and reality in gene expression profiling. J Clin Epidemiol 2010, 63:950-959.

41. Piaggi $P$, Lippi $C$, Fierabracci $P$, Maffei $M$, Calderone A, Mauri M Anselmino M, Cassano GB, Vitti P, Pinchera A, Landi A, Santini F: Artificial neural networks in the outcome prediction of adjustable gastric banding in obese women. PloS One 2010, 5:e13624.

42. Lee WJ, Chong K, Ser KH, Chen JC, Lee YC, Chen SC, Su YH, Tsai MH: Cpeptide predicts the remission of type 2 diabetes after bariatric surgery. Obes Surg 2012, 22:293-298.

43. Dixon JB, Chuang LM, Chong K, Chen SC, Lambert GW, Straznicky NE, Lambert EA, Lee WJ: Predicting the glycemic response to gastric bypass surgery in patients with type 2 diabetes. Diabetes Care.

44. Hayes MT, Hunt LA, Foo J, Tychinskaya Y, Stubbs RS: A model for predicting the resolution of type 2 diabetes in severely obese subjects following Roux-en Y gastric bypass surgery. Obes Surg 2011, 21:910-916.

45. Lee WJ, Hur KY, Lakadawala M, Kasama K, Wong SK, Chen SC, Lee YC, Ser $\mathrm{KH}$ : Predicting success of metabolic surgery: age, body mass index, C-peptide, and duration score. Surg Obes Relat Dis

46. le Roux CW, Welbourn R, Werling M, Osborne A, Kokkinos A, Laurenius A, Lönroth H, Fändriks L, Ghatei MA, Bloom SR, Olbers T: Gut hormones as mediators of appetite and weight loss after Roux-en- $Y$ gastric bypass. Ann Surg 2007, 246:780-785.

47. Pournaras DJ, Glicksman C, Vincent RP, Kuganolipava S, Alaghband-Zadeh J, Mahon D, Bekker JH, Ghatei MA, Bloom SR, Walters JR, Welbourn R, le Roux CW: The role of bile after Roux-en-Y gastric bypass in promoting weight loss and improving glycaemic control. Endocrinology 2012, 153:3613-3619.

48. le Roux CW, Aylwin SJ, Batterham RL, Borg CM, Coyle F, Prasad V, Shurey S, Ghatei MA, Patel AG, Bloom SR: Gut hormone profiles following bariatric surgery favor an anorectic state, facilitate weight loss, and improve metabolic parameters. Ann Surg 2006, 243:108-114.

49. Borg CM, le Roux CW, Ghatei MA, Bloom SR, Patel AG, Aylwin SJ: Progressive rise in gut hormone levels after Roux-en-Y gastric bypass suggests gut adaptation and explains altered satiety. Br J Surg 2006, 93:210-215.

50. Angrisani L, Lorenzo M, Borrelli V: Laparoscopic adjustable gastric banding versus Roux-en-Y gastric bypass: 5 -year results of a prospective randomized trial. Surg Obes Relat Dis 2007, 3:127-132, discussion 32-3.

51. Tice JA, Karliner L, Walsh J, Petersen AJ, Feldman MD: Gastric banding or bypass? A systematic review comparing the two most popular bariatric procedures. Am J Med 2008, 121:885-893.

52. O'Brien PE, MCPhail T, Chaston TB, Dixon JB: Systematic review of medium-term weight loss after bariatric operations. Obes Surg 2006, 16:1032-1040.

53. Kehagias I, Karamanakos SN, Argentou M, Kalfarentzos F: Randomized clinical trial of laparoscopic Roux-en-Y gastric bypass versus laparoscopic sleeve gastrectomy for the management of patients with $\mathrm{BMl}<50 \mathrm{~kg} / \mathrm{m} 2$. Obes Surg 2011, 21:1650-1656.

54. Clinical Issues Committee of American Society for Metabolic and Bariatric Surgery: Sleeve gastrectomy as a bariatric procedure. Surg Obes Relat Dis 2007, 3:573-576.

55. Himpens J, Dobbeleir J, Peeters G: Long-term results of laparoscopic sleeve gastrectomy for obesity. Ann Sur 2010, 252:319-324.

56. Laurenius A, Taha O, Maleckas A, Lonroth H, Olbers T: Laparoscopic biliopancreatic diversion/duodenal switch or laparoscopic Roux-en-Y gastric bypass for super-obesity-weight loss versus side effects. Surg Obes Relat Dis 2010, 6:408-414.

57. Buchwald $H$, Avidor $Y$, Braunwald $E$, Jensen MD, Pories W, Fahrbach $K$, Schoelles K: Bariatric surgery: a systematic review and meta-analysis. JAMA 2004, 292:1724-1737.

58. Sovik T, Aasheim ET, Taha O, Engstrom M, Fagerland MW, Bjorkman S, Kristinsson J, Birkeland Kl, Mala T, Olbers T: Weight loss, cardiovascular risk factors, and quality of life after gastric bypass and duodenal switch: a randomized trial. Ann Intern Med 2011, 155:281-291. 
59. Karamanakos SN, Vagenas K, Kalfarentzos F, Alexandrides TK: Weight loss, appetite suppression, and changes in fasting and postprandial ghrelin and peptide-YY levels after Roux-en-Y gastric bypass and sleeve gastrectomy: a prospective, double blind study. Ann Surg 2008, 247:401-407.

60. Prachand VN, Ward M, Alverdy JC: Duodenal switch provides superior resolution of metabolic comorbidities independent of weight loss in the super-obese (BMI > or $=50 \mathrm{~kg} / \mathrm{m} 2)$ compared with gastric bypass. J Gastrointest Surg 2010, 14:211-220.

61. Buchwald H, Estok R, Fahrbach K, Banel D, Jensen MD, Pories WJ, Bantle JP, Sledge I: Weight and type 2 diabetes after bariatric surgery: systematic review and meta-analysis. Am J Med 2009, 122:248-256, e5.

62. Hedberg J, Sundbom M: Superior weight loss and lower HbA1c 3 years after duodenal switch compared with Roux-en-Y gastric bypass-a randomized controlled trial. Surg Obes Relat Dis 2012, 8:338-343.

63. Schauer PR, Kashyap SR, Wolski K, Brethauer SA, Kirwan JP, Pothier CE, Thomas S, Abood B, Nissen SE, Bhatt DL: Bariatric surgery versus intensive medical therapy in obese patients with diabetes. N Engl J Med 2012, 366:1567-1576

64. Mingrone G, Panunzi S, De Gaetano A, Guidone C, laconelli A, Leccesi L, Nanni G, Pomp A, Castagneto M, Ghirlanda G, Rubino F: Bariatric surgery versus conventional medical therapy for type 2 diabetes. $N$ Engl J Med 2012, 366:1577-1585

65. Wei YF, Tseng WK, Huang CK, Tai CM, Hsuan CF, Wu HD: Surgically induced weight loss, including reduction in waist circumference, is associated with improved pulmonary function in obese patients. Surg Obes Relat Dis 2011, 7:599-604.

66. Gutschow CA, Collet P, Prenzel K, Holscher AH, Schneider PM: Long-term results and gastroesophageal reflux in a series of laparoscopic adjustable gastric banding. J Gastrointest Surg 2005, 9:941-948.

67. Prachand VN, Alverdy JC: Gastroesophageal reflux disease and severe obesity: Fundoplication or bariatric surgery? World J Gastroenterol 2010, 16:3757-3761

68. Greenburg DL, Lettieri CJ, Eliasson AH: Effects of surgical weight loss on measures of obstructive sleep apnea: a meta-analysis. Am J Med 2009, 122:535-542.

69. Boulet LP, Turcotte $H$, Martin J, Poirier P: Effect of bariatric surgery on airway response and lung function in obese subjects with asthma. Resp Med 2012, 106:651-660

70. Wilson PW, D'Agostino RB, Sullivan L, Parise H, Kannel WB: Overweight and obesity as determinants of cardiovascular risk: the Framingham experience. Arch Intern Med 2002, 162:1867-1872.

71. Sjostrom L, Peltonen M, Jacobson P, Sjostrom CD, Karason $K$, Wedel $H_{,}$ Ahlin S, Anveden Å, Bengtsson C, Bergmark G, Bouchard C, Carlsson B, Dahlgren S, Karlsson J, Lindroos AK, Lönroth H, Narbro K, Näslund I, Olbers T, Svensson PA, Carlsson LM: Bariatric surgery and long-term cardiovascular events. JAMA 2012, 307:56-65.

72. Hofso D, Nordstrand N, Johnson LK, Karlsen TI, Hager H, Jenssen T, Bollerslev J, Godang K, Sandbu R, Røislien J, Hjelmesaeth J: Obesity-related cardiovascular risk factors after weight loss: a clinical trial comparing gastric bypass surgery and intensive lifestyle intervention. Eur $J$ Endocrinol 2010, 163:735-745.

73. Alpert MA, Lambert CR, Panayiotou H, Terry BE, Cohen MV, Massey CV, Hashimi MW, Mukerii V: Relation of duration of morbid obesity to left ventricular mass, systolic function, and diastolic filling, and effect of weight loss. Am J Cardiol 1995, 76:1194-1197.

74. Lakhani M, Fein S: Effects of obesity and subsequent weight reduction on left ventricular function. Cardiol Rev 2011, 19:1-4

75. Ashrafian H, le Roux CW, Darzi A, Athanasiou T: Effects of bariatric surgery on cardiovascular function. Circulation 2008, 118:2091-2102.

76. Leibson CL, Williamson DF, Melton LJ, Palumbo PJ, Smith SA, Ransom JE, Schilling PL, Narayan KM: Temporal trends in BMl among adults with diabetes. Diabetes Care 2001, 24:1584-1589.

77. Benaiges D, Goday A, Ramon JM, Hernandez E, Pera M, Cano JF: Laparoscopic sleeve gastrectomy and laparoscopic gastric bypass are equally effective for reduction of cardiovascular risk in severely obese patients at one year of follow-up. Surg Obes Relat Dis 2011, 7:575-580.

78. MacDonald KG Jr, Long SD, Swanson MS, Brown BM, Morris P, Dohm GL, Pories WJ: The gastric bypass operation reduces the progression and mortality of non-insulin-dependent diabetes mellitus. J Gastrointest Surg 1997, 1:213-220, discussion 20.
79. laconelli A, Panunzi S, De Gaetano A, Manco M, Guidone C, Leccesi L, Gniuli D, Nanni G, Castagneto M, Ghirlanda G, Mingrone G: Effects of biliopancreatic diversion on diabetic complications: a 10-year follow-up. Diabetes Care 2011, 34:561-567.

80. Narbro K, Agren G, Jonsson E, Naslund I, Sjostrom L, Peltonen M: Pharmaceutical costs in obese individuals: comparison with a randomly selected population sample and long-term changes after conventional and surgical treatment: the SOS intervention study. Arch Intern Med 2002, 162:2061-2069.

81. Wang YC, McPherson K, Marsh T, Gortmaker SL, Brown M: Health and economic burden of the projected obesity trends in the USA and the UK. Lancet 2011, 378:815-825

82. Herpertz S, Kielmann R, Wolf AM, Langkafel M, Senf W, Hebebrand J: Does obesity surgery improve psychosocial functioning? A systematic review. Int J Obes Relat Metab Disord 2003, 27:1300-1314.

83. Narbro K, Agren G, Jonsson E, Larsson B, Naslund I, Wedel H, Sjostrom L: Sick leave and disability pension before and after treatment for obesity: a report from the Swedish Obese Subjects (SOS) study. Int J Obes Relat Metab Disord 1999, 23:619-624.

84. Cremieux PY, Buchwald H, Shikora SA, Ghosh A, Yang HE, Buessing M: A study on the economic impact of bariatric surgery. Am J Manag Care 2008, 14:589-596.

85. Neovius M, Narbro K, Keating C, Peltonen M, Sjoholm K, Agren G Sjostrom L, Carlsson L: Healthcare use during 20 years following bariatric surgery. JAMA 2012, 308:1132-1141.

86. Wadden TA, Sarwer DB, Fabricatore AN, Jones L, Stack R, Williams NS: Psychosocial and behavioral status of patients undergoing bariatric surgery: what to expect before and after surgery. Med Clin North Am 2007, 91:451-469, xi-xii.

87. Peltonen M, Lindroos AK, Torgerson JS: Musculoskeletal pain in the obese: a comparison with a general population and long-term changes after conventional and surgical obesity treatment. Pain 2003, 104:549-557

88. Traish AM, Feeley RJ, Guay A: Mechanisms of obesity and related pathologies: androgen deficiency and endothelial dysfunction may be the link between obesity and erectile dysfunction. FEBS J 2009, 276:5755-5767.

89. Kort HI, Massey JB, Elsner CW, Mitchell-Leef D, Shapiro DB, Witt MA Roudebush WE: Impact of body mass index values on sperm quantity and quality. J Androl 2006, 27:450-452.

90. Bastounis EA, Karayiannakis AJ, Syrigos K, Zbar A, Makri GG, Alexiou D: Sex hormone changes in morbidly obese patients after vertical banded gastroplasty. Eur Surg Res 1998, 30:43-47.

91. Sermondade N, Massin N, Boitrelle F, Pfeffer J, Eustache F, Sifer C, Czemichow S, Levy R: Sperm parameters and male fertility after bariatric surgery: three case series. Reprod Biomed Online 2012, 24:206-210.

92. Boots $C$, Stephenson MD: Does obesity increase the risk of miscarriage in spontaneous conception: a systematic review. Sem Reprod Med 2011, 29:507-513.

93. Escobar-Morreale HF, Botella-Carretero Jl, Alvarez-Blasco F, Sancho J, San Millan JL: The polycystic ovary syndrome associated with morbid obesity may resolve after weight loss induced by bariatric surgery. J Clin Endocrinol Metab 2005, 90:6364-6369.

94. Maggard MA, Yermilov I, Li Z, Maglione M, Newberry S, Suttorp M, Hilton L, Santry HP, Morton JM, Livingston EH, Shekelle PG: Pregnancy and fertility following bariatric surgery: a systematic review. JAMA 2008, 300:2286-2296

95. Dalfra MG, Busetto L, Chilelli NC, Lapolla A: Pregnancy and foetal outcome after bariatric surgery: a review of recent studies. J Matern-fetal Neonatal Med 2012, 25:1537-1543.

96. Karlsson J, Taft C, Ryden A, Sjostrom L, Sullivan M: Ten-year trends in health-related quality of life after surgical and conventional treatment for severe obesity: the SOS intervention study. Int J Obes (Lond) 2007, 31:1248-1261.

97. de Zwaan M, Enderle J, Wagner S, Muhlhans B, Ditzen B, Gefeller O, Mitchell JE, Muller A: Anxiety and depression in bariatric surgery patients: a prospective, follow-up study using structured clinical interviews. $J$ Affect Disord 2011, 133:61-68.

98. Hell E, Miller KA, Moorehead MK, Norman S: Evaluation of health status and quality of life after bariatric surgery: comparison of standard Roux-en-Y 
gastric bypass, vertical banded gastroplasty and laparoscopic adjustable silicone gastric banding. Obes Surg 2000, 10:214-219.

99. Hrabosky Jl, Masheb RM, White MA, Rothschild BS, Burke-Martindale $\mathrm{CH}$, Grilo CM: A prospective study of body dissatisfaction and concerns in extremely obese gastric bypass patients: 6 - and 12-month postoperative outcomes. Obes Surg 2006, 16:1615-1621.

100. Ratcliff MB, Eshleman KE, Reiter-Purtill J, Zeller MH: Prospective changes in body image dissatisfaction among adolescent bariatric patients: the importance of body size estimation. Surg Obes Relat Dis 2012, 8:470-475.

101. Sarwer DB, Wadden TA, Moore RH, Eisenberg MH, Raper SE, Williams NN: Changes in quality of life and body image after gastric bypass surgery. Surg Obes Relat Dis 2010, 6:608-614.

102. Zeller MH, Reiter-Purtill J, Ratcliff MB, Inge TH, Noll JG: Two-year trends in psychosocial functioning after adolescent Roux-en-Y gastric bypass. Surg Obes Relat Dis 2011, 7:727-732.

103. Colles SL, Dixon JB, O'Brien PE: Grazing and loss of control related to eating: two high-risk factors following bariatric surgery. Obesity (Silver Spring) 2008, 16:615-622.

104. Wong A, Fitzgerald RC: Epidemiologic risk factors for Barrett's esophagus and associated adenocarcinoma. Clin Gastroenterol Hepatol 2005, 3:1-10.

105. Csendes A, Burgos AM, Smok G, Burdiles P, Henriquez A: Effect of gastric bypass on Barrett's esophagus and intestinal metaplasia of the cardia in patients with morbid obesity. J Gastrointest Surg 2006, 10:259-264.

106. Verhave JC, Fesler P, Ribstein J, du Cailar G, Mimran A: Estimation of renal function in subjects with normal serum creatinine levels: influence of age and body mass index. Am J Kidney Dis 2005, 46:233-241.

107. Turgeon NA, Perez S, Mondestin M, Davis SS, Lin E, Tata S, Kirk AD, Larsen CP, Pearson TC, Sweeney JF: The impact of renal function on outcomes of bariatric surgery. J Am Soc Nephrol 2012, 23:885-894.

108. Navarro-Diaz M, Serra A, Romero R, Bonet J, Bayes B, Homs M, Perez N, Bonal J: Effect of drastic weight loss after bariatric surgery on renal parameters in extremely obese patients: long-term follow-up. J Am Soc Nephrol 2006, 17:S213-217.

109. Afshinnia F, Wilt TJ, Duval S, Esmaeili A, Ibrahim HN: Weight loss and proteinuria: systematic review of clinical trials and comparative cohorts. Nephrol Dial Transplant 2010, 25:1173-1183.

110. Li Z, Clark J, Diehl AM: The liver in obesity and type 2 diabetes mellitus. Clin Liver Dis 2002, 6:867-877.

111. Chavez-Tapia NC, Tellez-Avila Fl, Barrientos-Gutierrez T, Mendez-Sanchez N Lizardi-Cervera J, Uribe M: Bariatric surgery for non-alcoholic steatohepatitis in obese patients. Cochrane Database Syst Rev 2010, , 1: CD007340.

112. Sjostrom L, Gummesson A, Sjostrom CD, Narbro K, Peltonen M, Wedel $H$, Bengtsson C, Bouchard C, Carlsson B, Dahlgren S, Jacobson P, Karason K, Karlsson J, Larsson B, Lindroos AK, Lönroth H, Näslund I, Olbers T, Stenlöf K, Torgerson J, Carlsson LM, Swedish Obese Subjects Study: Effects of bariatric surgery on cancer incidence in obese patients in Sweden (Swedish Obese Subjects Study): a prospective, controlled intervention trial. Lancet Oncol 2009, 10:653-662.

113. Ashrafian H, Ahmed K, Rowland SP, Patel VM, Gooderham NJ, Holmes E, Darzi A, Athanasiou T: Metabolic surgery and cancer: protective effects of bariatric procedures. Cancer 2011, 117:1788-1799.

114. Longitudinal Assessment of Bariatric Surgery (LABS) Consortium, Flum DR, Belle SH, King WC, Wahed AS, Berk P, Chapman W, Pories W, Courcoulas A, McCloskey C, Mitchell J, Patterson E, Pomp A, Staten MA, Yanovski SZ, Thirlby $\mathrm{R}$, Wolfe B: Perioperative safety in the longitudinal assessment of bariatric surgery. N Engl J Med 2009, 361:445-454.

115. Nguyen NT, Rivers R, Wolfe BM: Factors associated with operative outcomes in laparoscopic gastric bypass. J Am Coll Surg 2003, 197:548-555, discussion 55-57.

116. Smith MD, Patterson E, Wahed AS, Belle SH, Berk PD, Courcoulas AP, Dakin GF, Flum DR, Machado L, Mitchell JE, Pender J, Pomp A, Pories W, Ramanathan R, Schrope B, Staten M, Ude A, Wolfe BM: Thirty-day mortality after bariatric surgery: independently adjudicated causes of death in the longitudinal assessment of bariatric surgery. Obes Surg 2011. 21:1687-1692.

117. Carucci LR, Turner MA, Conklin RC, DeMaria EJ, Kellum JM, Sugerman $H J$ : Roux-en-Y gastric bypass surgery for morbid obesity: evaluation of postoperative extraluminal leaks with upper gastrointestinal series. Radiology 2006, 238:119-127.
118. Simon TE, Scott JA, Brockmeyer JR, Rice RC, Frizzi JD, Husain FA, Choi YU: Comparison of staple-line leakage and hemorrhage in patients undergoing laparoscopic sleeve gastrectomy with or without Seamguard. Am Surg 2011, 77:1665-1668.

119. Mitchell MT, Carabetta JM, Shah RN, O'Riordan MA, Gasparaitis AE, Alverdy JC: Duodenal switch gastric bypass surgery for morbid obesity: imaging of postsurgical anatomy and postoperative gastrointestinal complications. AJR Am J Roentgenol 2009, 193:1576-1580.

120. Cunneen SA: Review of meta-analytic comparisons of bariatric surgery with a focus on laparoscopic adjustable gastric banding. Surg Obes Relat Dis 2008, 4:547-55.

121. Mehran A, Szomstein S, Zundel N, Rosenthal R: Management of acute bleeding after laparoscopic Roux-en-Y gastric bypass. Obes Surg 2003, 13:842-847.

122. Sakran N, Assalia A, Sternberg A, Kluger Y, Troitsa A, Brauner E, Van Cauwenberge S, De Visschere M, Dillemans B: Smaller staple height for circular stapled gastrojejunostomy in laparoscopic gastric bypass: early results in 1,074 morbidly obese patients. Obes Surg 2011, 21:238-243.

123. Rabl C, Peeva S, Prado K, James AW, Rogers SJ, Posselt A, Campos GM: Early and late abdominal bleeding after Roux-en-Y gastric bypass: sources and tailored therapeutic strategies. Obes Surg 2011, 21:413-420.

124. Frezza EE, Reddy S, Gee LL, Wachtel MS: Complications after sleeve gastrectomy for morbid obesity. Obes Surg 2009, 19:684-687.

125. Daskalakis M, Berdan Y, Theodoridou S, Weigand G, Weiner RA: Impact of surgeon experience and buttress material on postoperative complications after laparoscopic sleeve gastrectomy. Surg Endosc 2011, 25:88-97.

126. Dillemans B, Sakran N, Van Cauwenberge S, Sablon T, Defoort B, Van Dessel E, Akin F, Moreels N, Lambert S, Mulier J, Date R, Vandelanotte M, Feryn T, Proot L: Standardization of the fully stapled laparoscopic Rouxen-Y gastric bypass for obesity reduces early immediate postoperative morbidity and mortality: a single center study on 2606 patients. Obes Surg 2009, 19:1355-1364.

127. Nguyen NT, Wilson SE: Complications of antiobesity surgery. Nat Clin Pract Gastroenterol Hepatol 2007, 4:138-147.

128. Crea N, Pata G, Di Betta E, Greco F, Casella C, Vilardi A, Mittempegher F: Long-term results of biliopancreatic diversion with or without gastric preservation for morbid obesity. Obes Surg 2011, 21:139-145.

129. Rodriguez A, Mosti M, Sierra M, Perez-Johnson R, Flores S, Dominguez G, Sánchez H, Zarco A, Romay K, Herrera MF: Small bowel obstruction after antecolic and antegastric laparoscopic Roux-en-Y gastric bypass: could the incidence be reduced? Obes Surg 2010, 20:1380-1384.

130. Nguyen NT, Stevens CM, Wolfe BM: Incidence and outcome of anastomotic stricture after laparoscopic gastric bypass. J Gastrointest Surg 2003, 7:997-1003.

131. Mathew A, Veliuona MA, DePalma FJ, Cooney RN: Gastrojejunal stricture after gastric bypass and efficacy of endoscopic intervention. Dig Dis Sci 2009, 54:1971-1978.

132. Bolen SD, Chang HY, Weiner JP, Richards TM, Shore AD, Goodwin SM, Johns RA, Magnuson TH, Clark JM: Clinical outcomes after bariatric surgery: a five-year matched cohort analysis in seven US states. Obes Surg 2012, 22:749-763.

133. Csendes A, Torres J, Burgos AM: Late marginal ulcers after gastric bypass for morbid obesity. Clinical and endoscopic findings and response to treatment. Obes Surg 2011, 21:1319-1322.

134. Thornton CM, Rozen WM, So D, Kaplan ED, Wilkinson S: Reducing band slippage in laparoscopic adjustable gastric banding: the mesh plication pars flaccida technique. Obes Surg 2009, 19:1702-1706.

135. Bernante P, Francini Pesenti F, Toniato A, Zangrandi F, Pomerri F, Pelizzo MR: Obstructive symptoms associated with the $9.75-\mathrm{cm}$ Lap-Band in the first 24 hours using the pars flaccida approach. Obes Surg 2005, 15:357-360.

136. Allen JW: Laparoscopic gastric band complications. Med Clin North Am 2007, 91:485-497, xii.

137. O'Brien PE, Dixon JB: Weight loss and early and late complications-the international experience. Am J Surg 2002, 184:42S-45S.

138. Favretti F, Segato G, Ashton D, Busetto L, De Luca M, Mazza M, Ceoloni A, Banzato O, Calo E, Enzi G: Laparoscopic adjustable gastric banding in 1,791 consecutive obese patients: 12-year results. Obes Surg 2007, 17:168-175. 
139. Chakravarty PD, McLaughlin E, Whittaker D, Byrne E, Cowan E, Xu K, Bruce DM, Ford JA: Comparison of laparoscopic adjustable gastric banding (LAGB) with other bariatric procedures; a systematic review of the randomised controlled trials. Surgeon 2012, 10:172-182.

140. Ziegler O, Sirveaux MA, Brunaud L, Reibel N, Quilliot D: Medical follow up after bariatric surgery: nutritional and drug issues. General recommendations for the prevention and treatment of nutritional deficiencies. Diabet Metab 2009, 35:544-557.

141. Fujioka K: Follow-up of nutritional and metabolic problems after bariatric surgery. Diabetes Care 2005, 28:481-484.

142. Roberson EN, Gould JC, Wald A: Urinary and fecal incontinence after bariatric surgery. Dig Dis Sci 2010, 55:2606-2613.

143. Poylin V, Serrot FJ, Madoff RD, Ikramuddin S, Mellgren A, Lowry AC, Melton GB: Obesity and bariatric surgery: a systematic review of associations with defecatory dysfunction. Colorectal Dis 2011, 13:e92-103.

144. Tack J, Arts J, Caenepeel P, De Wulf D, Bisschops R: Pathophysiology, diagnosis and management of postoperative dumping syndrome. Nat Rev Gastroenterol Hepatol 2009, 6:583-590.

145. Goldfine AB, Mun EC, Devine E, Bernier R, Baz-Hecht M, Jones DB, Schneider BE, Holst JJ, Patti ME: Patients with neuroglycopenia after gastric bypass surgery have exaggerated incretin and insulin secretory responses to a mixed meal. J Clin Endocrinol Metab 2007, 92:4678-4685.

146. Rabiee A, Magruder JT, Salas-Carrillo R, Carlson O, Egan JM, Askin FB, Elahi D, Andersen DK: Hyperinsulinemic hypoglycemia after Roux-en-Y gastric bypass: unraveling the role of gut hormonal and pancreatic endocrine dysfunction. J Surg Res 2011, 167:199-205.

147. Spanakis E, Gragnoli C: Successful medical management of status postRoux-en-Y-gastric-bypass hyperinsulinemic hypoglycemia. Obes Surg 2009, 19:1333-1334.

148. Patti ME, McMahon G, Mun EC, Bitton A, Holst JJ, Goldsmith J, Hanto DW, Callery M, Arky R, Nose V, Bonner-Weir S, Goldfine AB: Severe hypoglycaemia post-gastric bypass requiring partial pancreatectomy: evidence for inappropriate insulin secretion and pancreatic islet hyperplasia. Diabetologia 2005, 48:2236-2240.

149. Boza C, Gamboa C, Perez G, Crovari F, Escalona A, Pimentel F, Raddatz A, Guzman S, Ibáñez L: Laparoscopic adjustable gastric banding (LAGB): surgical results and 5-year follow-up. Surg Endosc 2011, 25:292-297.

150. Hamdan K, Somers S, Chand M: Management of late postoperative complications of bariatric surgery. Br J Surg 2011, 98:1345-1355.

151. Shimizu H, Timratana P, Schauer PR, Rogula T: Review of metabolic surgery for type 2 diabetes in patients with a BMI $<35 \mathrm{~kg} / \mathrm{m}(2)$. J Obes 2012, 2012:147256

152. Mirshahi UL, Still CD, Masker KK, Gerhard GS, Carey DJ, Mirshahi T: The MC4R(I251L) allele is associated with better metabolic status and more weight loss after gastric bypass surgery. J Clin Endocrinol Metab 2011, 96 E2088-2096.

153. Potoczna N, Branson R, Kral JG, Piec G, Steffen R, Ricklin T, Hoehe MR, Lentes KU, Horber FF: Gene variants and binge eating as predictors of comorbidity and outcome of treatment in severe obesity. J Gastrointest Surg 2004, 8:971-981, discussion 81-2.

Pre-publication history

The pre-publication history for this paper can be accessed here: http://www.biomedcentral.com/1741-7015/11/8/prepub

doi:10.1186/1741-7015-11-8

Cite this article as: Neff et al:: Bariatric surgery: the challenges with candidate selection, individualizing treatment and clinical outcomes. BMC Medicine 2013 11:8.

\section{Submit your next manuscript to BioMed Central and take full advantage of:}

- Convenient online submission

- Thorough peer review

- No space constraints or color figure charges

- Immediate publication on acceptance

- Inclusion in PubMed, CAS, Scopus and Google Scholar

- Research which is freely available for redistribution 